\title{
Influence of Fructose and Fatty-Rich Diet Combined with Vanadium on Bone Marrow Cells
}

\author{
Mirosław Krośniak • Monika A. Papież • \\ Joanna Kaczmarczyk • Renata Francik • \\ Maria G. Panza • Vincenzo Covelli • Ryszrad Gryboś
}

Received: 9 May 2013 / Accepted: 7 August 2013 / Published online: 29 August 2013

(C) The Author(s) 2013. This article is published with open access at Springerlink.com

\begin{abstract}
The aim of the study is to investigate the influence of diet treatment on bone marrow cells. Normal male Wistar rats were divided into six groups ( $n=6$ per group): control with normal diet (C), increased fructose (31\% $w / w$ in fodder) (Fr) and high fatty (30\% w/w of animal fat in fodder) diet $(\mathrm{Fa})$, and the same diets with vanadium complex $\left(\left[\mathrm{VO}\left(4,4^{\prime}\right.\right.\right.$ $\left.\left.\left.\mathrm{Me}_{2}-2,2^{\prime} \mathrm{Bpy}\right)_{2}\right] \mathrm{SO}_{4}\right) \cdot \mathrm{H}_{2} \mathrm{O}(\mathrm{CV}, \mathrm{FrV}$ and $\mathrm{FaV})$. During 5 weeks, the animals had unlimited access to food and water. Immediately after anaesthetizing and sacrificing the animals, bone marrow smears were prepared from the femurs. Different types of cell lines in the animal smears were examined under the microscope: erythroid line, myeloid line, monocytic line, megakariocytic line and lymphoid line. Addition of fructose or animal fat had evident influence on the proportional composition of the bone marrow cells. In erythroid precursors, addition of both investigated products resulted in a statistically significant increase of percentage of this type of cells. A reverse effect was observed for the lymphoid cell line where
\end{abstract}

Maria G. Panza and Vincenzo Covelli are students from the Faculty of Pharmacy, Nutritional and Health Sciences, Calabria University, 87036 Arcavacata di Rende, Italy and participants of the Erasmus Program in the Department of Food Chemistry and Nutrition, Medical College, Jagiellonian University (Poland)

M. Krośniak $(\bowtie) \cdot J$. Kaczmarczyk · M. G. Panza • V. Covelli Department of Food Chemistry and Nutrition, Medical College, Jagiellonian University, 9 Medyczna St., 30-688 Kraków, Poland e-mail: mfkrosni@cyf-kr.edu.pl

M. A. Papież

Department of Cytobiology, Medical College, Jagiellonian

University, 9 Medyczna St., 30-688 Kraków, Poland

R. Francik

Department of Bioorganic Chemistry, Medical College, Jagiellonian

University, 9 Medyczna St., 30-688 Kraków, Poland

R. Gryboś

Faculty of Chemistry, Jagiellonian University, 30-060 Kraków,

Poland addition of both tested diets decreased quantity of these cells in comparison to the control diet. In the same lines, addition of vanadium intensified the observed changes. In the case of other types of cell lines, statistically significant changes were not observed.

Keywords Bone marrow cells $\cdot$ Fructose $\cdot$ Fatty diet . Vanadium

\section{Introduction}

Bone marrow is an indispensable structure in the vertebrate organism. It plays two important roles: produces all blood cells and participates in immunological reactions of the organism. Cells at different stages of development are present in the bone marrow. In the case of rats, the main cell line present in marrow is myeloid - it usually amounts to $30-50 \%$ of all cells. The second one is erythroid. Other lines: monocytic, megakariocytic and lymphoid constitute a lower percentage [1-3].

The marrow and its cell creation are very sensitive to a large number of chemicals and external factors, such as radiation, malnutrition and others. Toxic influence of chemicals or external factors on marrow cells can cause hypoaplasia or, in an extreme case, aplasia. Histological and cytological studies of the bone marrow are also one of the basic methods of research on the possible influence of newly introduced medicines, especially in pre-clinical investigation [4]. Influence of numerous chemical substances on bone marrow has been observed [5-8]. All essential food components are necessary for correct cell production in the marrow [9]. Low physical activity and changes in the way of living in more affluent countries provoke numerous diseases, especially diabetes, obesity and cardiovascular diseases [10]. In the case of diabetes type 2, nutrition is one of the elements of prevention or treatment. For a long time, fructose, which has a low glycemic 
index, was recommended as an alternative for sucrose or glucose $[11,12]$. At present, a fatty diet is also proposed as one of the ways for blood glucose control [13]. Information in publications about the influence of fructose and a fatty diet on different marrow cell percentage is infrequent. In cases of diabetes and obesity, changing percentage of marrow cells can be one of the ways of treatment. The anti-diabetic effect of vanadium inorganic salts were discovered in an animal experiment concerning diabetes treatment. Since then, the anti-diabetic activity of different vanadium compounds has been investigated in particular for organic compounds [14-17]. Diabetes type 2 is more frequent than type 1 . In the initial stage of diabetes type 2 , only diet or diet with medication, very often in tablet form, is used. At a later stage, insulin injections are necessary. Insulin injections are unpleasant for patients, and for that reason, methods are sought for to delay this moment in time. Vanadium treatment may be useful in diabetes treatment and its influence on all physiological parameters must be investigated. Since marrow cells are very sensitive, potential negative effects on the bone marrow may occur after administration of vanadium compounds.

\section{Aim \\ The aim of the present study was to investigate the little known influence of dietary modifications on morphological changes in the bone marrow.}

\section{Materials and Methods}

\section{Food for Animals}

All diets for animals were prepared especially for this experiment in the Department of Food Chemistry and Nutrition. Table 1 presents the components used.

\section{Animals}

The experiment was conducted on 3-month-old male Wistar rats, weighing $250 \pm 15 \mathrm{~g}$ and caged under a temperature of $23{ }^{\circ} \mathrm{C}$, humidity $50-60 \%$, and light-dark cycle $(12 / 12 \mathrm{~h})$. Each group consisted of six animals. During 5 weeks of experiment, each group of animals was fed a different diet: control $(\mathrm{C})$, fructose $(\mathrm{Fr})$, fatty $(\mathrm{Fa})$, control + vanadium $(\mathrm{CV})$, fructose + vanadium $(\mathrm{FrV})$ and fat + vanadium $(\mathrm{FaV})$. The composition is shown in Table 1. The animals had free access to food and water, which were measured every week. The groups of animals fed with vanadium were treated with the vanadium complex ([VO $\left.\left.\left(4,4^{\prime} \mathrm{Me}_{2}-2,2^{\prime} \mathrm{Bpy}\right)_{2}\right] \mathrm{SO}_{4}\right) \cdot \mathrm{H}_{2} \mathrm{O}$ with a dose of $20 \mathrm{mg} / \mathrm{kg}$ one time daily (at 9 a.m.) during 5 weeks directly to the stomach by gavage. After 5 weeks of the
Table 1 Percentage composition of used diets in experiment

\begin{tabular}{|c|c|c|c|}
\hline Component & $\begin{array}{l}\text { Control diet } \\
\text { (C) }[\%]\end{array}$ & $\begin{array}{l}\text { Fructose diet } \\
\text { (Fr) }[\%]\end{array}$ & $\begin{array}{l}\text { Fatty diet } \\
(\mathrm{Fa})[\%]\end{array}$ \\
\hline Starch & 62.0 & 31.0 & 32.0 \\
\hline Casein & 20.0 & 20.0 & 20.0 \\
\hline Rapeseed oil & 5.0 & 5.0 & 5.0 \\
\hline Fructose & - & 31.0 & - \\
\hline Lard & - & - & 30.0 \\
\hline Calcium carbonate & 2.8 & 2.8 & 2.8 \\
\hline $\mathrm{Ca}_{3}\left(\mathrm{PO}_{4}\right)_{2}$ & 2.9 & 2.9 & 2.9 \\
\hline Lecithin & 1.0 & 1.0 & 1.0 \\
\hline $\mathrm{NaCl}$ & 0.3 & 0.3 & 0.3 \\
\hline Cellulose & 4.7 & 4.7 & 4.7 \\
\hline $\begin{array}{l}\text { Minerals and vitamin mix } \\
(\text { contain } 0.75 \% \text { of } \mathrm{Fe})\end{array}$ & 1.0 & 1.0 & 1.0 \\
\hline $\mathrm{MgO}$ & 0.07 & 0.07 & 0.07 \\
\hline $\mathrm{K}_{2} \mathrm{SO}_{4}$ & 0.23 & 0.23 & 0.23 \\
\hline
\end{tabular}

experiment, the animals were anesthetized and the femoral bone from the left back leg was prepared; the marrow from this bone was immediately distributed on the microscope glass and dried at room temperature.

The fructose content used in this experiment was only $31 \%$ because we wanted to study higher than average - but not high - content of this carbohydrate and its influence on analyzed parameters. Selected vanadium complex was synthesized at the Faculty of Chemistry of Jagiellonian University in Kraków; in a previous study, it demonstrated low toxicity and anti-diabetic activity. Purity of the compound was confirmed by spectrophotometric methods. A dose of $20 \mathrm{mg} / \mathrm{kg}$ was used as $1 / 20$ of $\mathrm{LD}_{50}$ of this substance.

The experiments were performed in accordance with legal requirements, under a license granted by the Local Commission of ethics in Krakow.

\section{Staining of Bone Marrow Smears}

One day after drying the prepared microscope glass containing marrow cells, the material was stained using MayGrunwald reagent for $5 \mathrm{~min}$. After that, a similar amount of water was added for $3 \mathrm{~min}$. Then the colorant was poured off and the Giemsa colorant (diluted two times) was added for $40 \mathrm{~min}$. After that time, the samples were washed and air-dried in room temperature and secured in a box for further microscopic analysis.

\section{Microscopic Observation}

All marrow samples were examined using an OLYMPUS CX41 microscope and a $1,000 \times$ zoom. Pictures (10-15 per each sample) were recorded using an OLYMPUS Camedia 
C-5050 camera. A picture analysis covered the places where cells were correctly colorized, monolayer and did not overlap. A minimal number of all marrow cells for five basal lines in each animal was $>1,500$. Observed marrow cells were counted manually as five basal lines: erythroid precursors, myeloid, monocytic, megakariocytic and lymphoid. The percentage of different cell lines was calculated as the number of cells of a given line in relation to the total number of all counted cells of the bone marrow. Sample microscope pictures are presented in Figs. 1, 2 and 3.

\section{Statistical Analysis}

Results of the observation for different marrow cells were calculated as a percentage of a total number of measured cells. Statistical analysis was performed using Statistica 9 and GraphPad Prism software.

\section{Results}

Body mass growth, food and water consumption are shown in Table 2.

\section{Body Mass Growth}

The type of used diet had evident influence on body mass growth (Table 2). Mean body mass growth was highest in the group with fructose diet and lowest in the vanadium-treated control group.

\section{Food Consumption}

Food consumption was associated with used diet in this case as well (Table 2). In the case of groups consisting of animals not treated with vanadium, the lowest consumption was observed in the group with fatty diet and highest in the control group. The

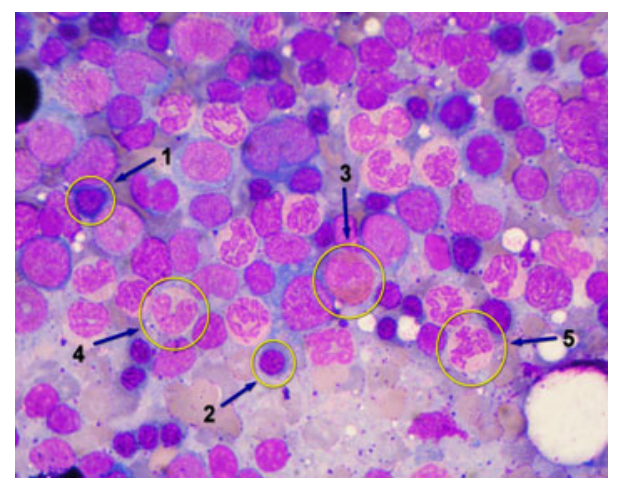

Fig. 1 Bone marrow smear. (1) basophil, (2) eosinophil, (3) segmented eosinophil, (4) banded neutrophil, (5) segmented neutrophil

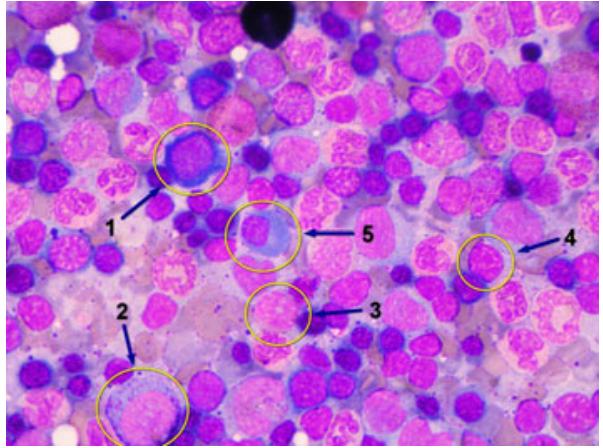

Fig. 2 Bone marrow smear. (1) proerythroblast, (2) promyelocyte, (3) myelocyte, (4) lymphocyte, (5) plasmocyte

addition of vanadium statistically increased food consumption in all diets in comparison to not treated animals.

\section{Water Consumption}

The profile of water consumption in the present investigation was similar to the food consumption (Table 2). Addition of investigated vanadium complex statistically increased water consumption in different diets in comparison to diets which did not contain vanadium.

\section{Erythroid Precursors}

As Fig. 4a shows, both additions to diet (fat and fructose) increased the percentage of erythroblast line in the bone marrow cells. A minimal percentage was observed for the control group (C), $42.7 \%$. The addition of vanadium compound (CV group) increased the percentage to $53.7 \%$. In animals with fructose diet ( $\mathrm{Fr}$ ) erythroid line precursors as a percentage of total marrow cells amounted to $49.9 \%$, and this result was similar for the animals with fatty $\operatorname{diet}(\mathrm{Fa}), 50.8 \%$. The administration of vanadium complex increased the above-mentioned percentage in both animal groups (FrV and $\mathrm{FaV}$ ) to $57.4 \%$ and $55.8 \%$, respectively. The biggest change of percentage of erythroid precursors was observed between

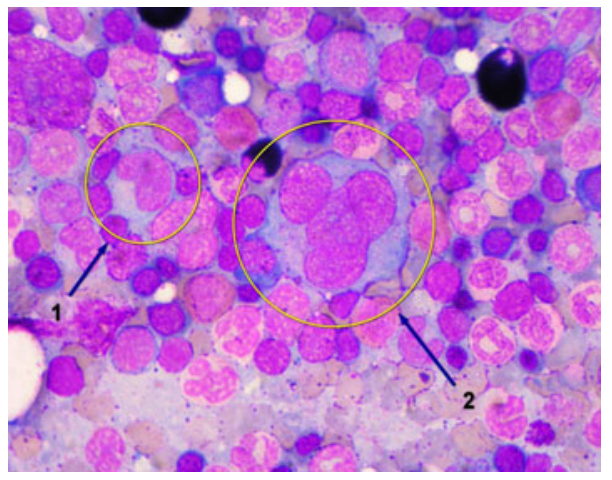

Fig. 3 Bone marrow smear. (1) monocyte, (2) promegakaryocyte 
Table 2 Body mass growth, food and water consumption in investigated groups of animals

\begin{tabular}{lccc}
\hline Group & $\begin{array}{l}\text { Body mass } \\
\text { growth }(\mathrm{g})\end{array}$ & $\begin{array}{l}\text { Food consumption } \\
(\mathrm{g} / 1 \text { rat/35 days })\end{array}$ & $\begin{array}{c}\text { Water consumption } \\
(\mathrm{mL} / 1 \text { rat/35 days })\end{array}$ \\
\hline $\mathrm{C}$ & $113.9 \pm 15.9$ & $657.7 \pm 46.63$ & $932,68 \pm 105.69$ \\
$\mathrm{Fr}$ & $132.2 \pm 12.0$ & $624.61 \pm 40.33$ & $883.16 \pm 11.06$ \\
$\mathrm{Fa}$ & $125.2 \pm 20.9$ & $471.55 \pm 24.45$ & $779.25 \pm 31.71$ \\
$\mathrm{CV}$ & $86.3 \pm 13.3$ & $829.35 \pm 9.55$ & $1,065.43 \pm 92.64$ \\
$\mathrm{FrV}$ & $119.7 \pm 19.4$ & $812.6 \pm 9.20$ & $986.13 \pm 129.99$ \\
$\mathrm{FaV}$ & $102.2 \pm 28.2$ & $655.13 \pm 44.55$ & $1,023.91 \pm 38.40$ \\
\hline
\end{tabular}

the control and the control with vanadium groups, $26 \%$. Between fructose and fructose with vanadium, the increase amounted to $15 \%$, and between fatty and fatty with vanadium, the increase amounted to $9 \%$.

The differences were statistically significant for the three groups: C vs. CV $(p<0.05), \mathrm{C}$ vs. FrV $(p<0.001)$ and $\mathrm{C}$ vs. $\mathrm{FaV}(p<0.01)$. All used additions to the control diet: fructose, fat and vanadium increased the percentage of erythroblast precursors. Vanadium addition to the fructose or fatty diet increased the percentage of erythroblast lines.

\section{Myeloid Line}

Relatively smallest differences were observed for myeloid line (Fig. 4b). Very similar results were obtained for all groups of animals. A minimal decrease (about $3 \%$ ) of the myeloid line was observed in the groups of animals not treated with vanadium in comparison to the control group. A higher but not significant decrease was observed in vanadium-treated animals. Adding vanadium to the control diet decreased the myeloid line by about $6 \%$. Addition of vanadium to the fructose diet decreased the myeloid line by about $5 \%$, but in the case of the fatty diet, the addition of vanadium decreased the myeloid line by only about $2 \%$.

\section{Monocytic Line}

In this case, very clear differences were observed for each type of diet (Fig. 4c). Fatty diet statistically decreased the monocytic line by about $70 \%(p<0.01)$ in comparison to the control group. An influence of fructose was also observed. In this case, the decrease amounted to about $20 \%$ in comparison to the control group, but it was not significant $(p=0.11)$. Vanadium administration showed a decrease of the monocytic line for both the control and fructose diet (37\% and $20 \%$, respectively). In the case of fatty diet, an inversed trend was observed. Used vanadium organic complex statistically prevented the decrease in this cell line induced by the diet rich in fatty acid. The observed differences need to be confirmed in subsequent studies using a much larger number of bone marrow cells. This cell line is weakly presented in the bone marrow.

\section{Megakariocytic Line}

In the megakariocytic line, some differences between the groups were also observed (Fig. 4d). Unfortunately, the number of observed megakariocytic cells was very small and therefore it is very difficult to write about differences. However, it was observed that vanadium treatment affected a decrease of the megakariocytic line in all animal groups in comparison to rats not treated with vanadium. Additionally, changes resulting from other diets were observed. It was observed that fructose diet affected a decrease of this cell line in comparison to the control group. Similarly, decrease of megakariocytic line was observed for fatty diet. All the differences were not significant due to individual differences between the rats.

\section{Lymphoid Line}

Changes between the examined groups in the lymphocytes line are very interesting (Fig. 4e). The addition of fructose or fat to the diet caused a decrease of the lymphoid line in comparison to the control diet ( $23 \%$ and $21 \%$, respectively), but it was not statistically significant. In all vanadium-treated animals, a decrease of the lymphoid line in comparison to the vanadium not treated animals was observed. The decrease of the lymphoid line between the control and the control with vanadium groups amounted to $33 \%$, between the fructose and the fructose with vanadium, $30 \%$, and between the fatty and the fatty with vanadium, $28 \%$. These differences were not significant. Addition of vanadium in all types of diet intensified the decrease of the percentage of lymphocytes in marrow cells and was statistically significant.

\section{Discussion}

Diabetes mellitus, especially type 2 , is associated with aging and obesity. An increase of the glucose level is associated with insulin resistance. Applying a diet at the beginning of this illness is one of the methods, or a helping method, in blood glucose controlling. A diet with fructose as an alternative to sucrose is/was one of the options recommended to patients $[11,12]$. Unfortunately, a negative effect of pure fructose in animal models has been observed after high sugar consumption, which increases insulin resistance in target cells and causes negative changes in blood biochemical parameters. A similar observation was reported in human blood as well. The fatty diet is the second possibility to lower blood glucose - the method used by people who want to lower their body mass [13]. Presently, this method is applied by thousands/millions 
Fig. 4 Percentage of bone marrow cells lines $(C)$ control, $(F r)$ fructose diet, $(\mathrm{Fa})$ fatty diet, $(\mathrm{CV})$ control with vanadium, $(\mathrm{Fr} V)$ fructose diet with vanadium, $(\mathrm{FaV})$ fatty diet with vanadium). a Erythroid precursors in different groups of animals (significant differences between groups: $\mathrm{C}$ versus $\mathrm{CV} p<0.05, \mathrm{FrV} p<0.001$ and $\mathrm{FaV} p<0.01$ ), b myeloid line in different groups of animals (no statistical differences), $\mathbf{c}$ monocytic line in different groups of animals (significant differences between groups $(p<0.05)$ : $\mathrm{Fa}$ versus $\mathrm{C}, \mathrm{Fr}, \mathrm{CV}, \mathrm{FrV}$ and $\mathrm{FaV}$ ), $\mathbf{d}$ megakariocytic line in different groups of animals (standard deviation is too big and it is difficult to make a statistical analysis), e lymphoid line in different groups of animals (significant differences between groups $(p<0.05)$ : $\mathrm{FrV}$ and $\mathrm{FaV}$ versus $\mathrm{C}, \mathrm{Fr}, \mathrm{Fa}$ and $\mathrm{CV}$ )

of people around the world. The animal fat used in our experiment is rich in saturated fat acids. It can provoke cardiovascular illness, obesity and diabetes. Some long-term experiments with fatty diet in animals demonstrate adaptive mechanisms and correction of biochemical parameters in the blood, such as glucose or triglycerides.

In the beginning of applying this method, paradoxically, an improvement of principal biochemical parameters in blood has been observed, but long-term investigations are continued, and at present, it is difficult to talk about future positive or negative results of this diet. For more than 20 years, vanadium compounds have been investigated in animal models of diabetes as an auxiliary method in the treatment of this illness. Some interesting vanadium organic ligands are investigated in human diabetes treatment. At this moment, there is no clear information about the influence of both the fructose and fatty diets with vanadium on the organism performance associated with blood creation. Bone marrow is an essential tissue which produces all blood cells. Incorrect cell production is most often associated with the white blood cell lines. Besides, this tissue is very sensitive to all changes associated with essential substance delivery. The treatment with an increased level of fructose, animal fat and/or vanadium presented in this work has been investigated as a new possibility of extending our knowledge about biological effects of the chosen methods used in the blood glucose control.

Numerous animal and human investigations show that high fructose diet can induce and provoke metabolic disorderobesity, diabetes, dyslipidemia, hypertension [18, 19]. Other investigations reported that small consumption of fructose, especially from fruits, has a positive effect on the organism and can protect it against diabetes type $2[18,20]$. Our knowledge about the influence of fructose on bone marrow cells is very limited especially as far as in vivo experiments are concerned. Fructose/lysine browning products were examined by MacGregor et al. [21], and they did not show influence on clastogenicity in mouse bone marrow. They did not count different marrow cell lines. Besides, the fructose used was not pure but fructose browning product after thermal processing. Fructose in the dose used in our experiment statistically influences the percentage of bone marrow cells. The percentage of cells from the erythroid line is increased, but the percentage of lymphoid is decreased.
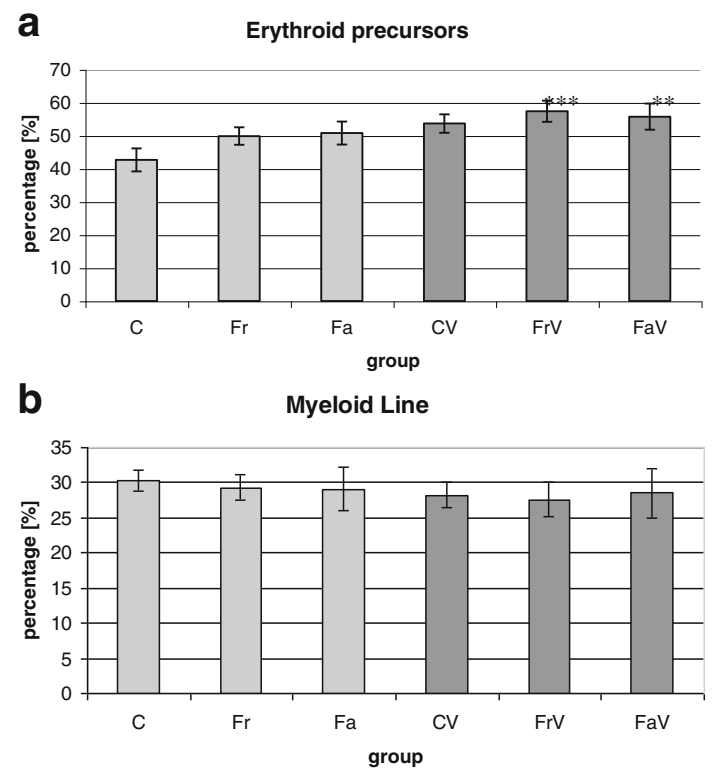

C

Monocytic line

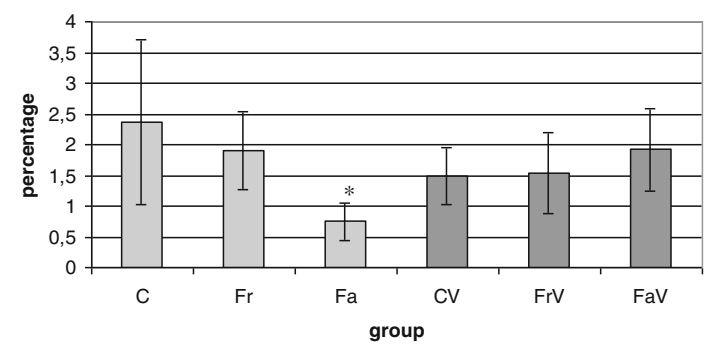

d Megacariocytic line

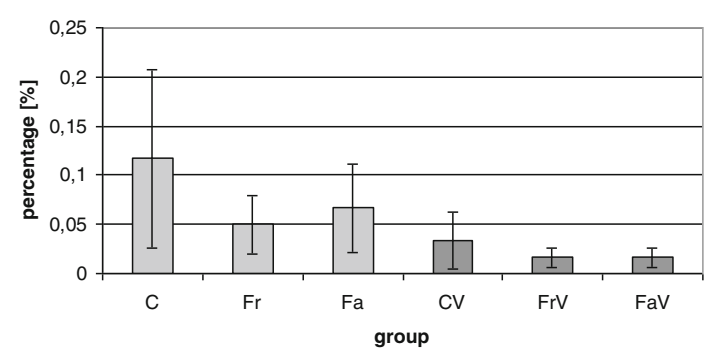

e

Lymphoid line

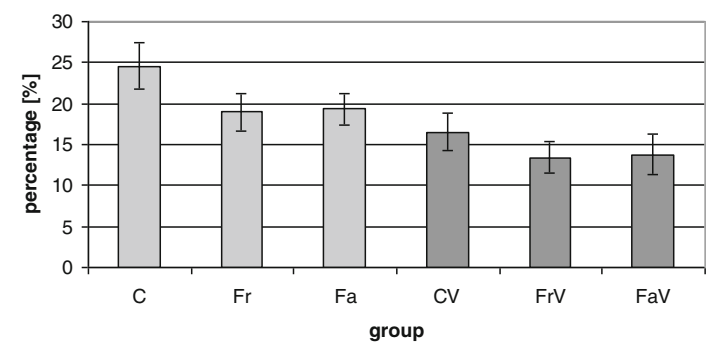

Vanadium inorganic compounds in high doses show toxic effect during animal investigation. Presently, organic ligand vanadium compounds with low toxic effects are investigated. These compounds have higher anti-diabetic activity, and some of them are tested in patients [22]. In research investigations of other authors, biochemical changes in serum or plasma are 
usually measured while other parameters as blood morphology or image of marrow bone cells are not. Sometimes the influence of vanadium compounds on peripheral blood shows stimulation of eryptosis [23]. This can have a negative influence on erythrocyte time life and can explain an increase of the erythroid line percentage in the marrow bone. However, other investigations present toxic effects of heavy metals as lead, cadmium and mercury on anaemia [24, 25]; influence of transitional metals, essential for organisms, on blood cell creation in the marrow is little known.

All results in this study show a high influence of fructose and fatty diet on a percentage of different cells in the bone marrow and interaction of both diets with vanadium organic ligand. Help in diabetes treatment by diets can statistically change the profile of bone marrow cells in patients and can influence the total organism homeostasis. An increase of the percentage of the red blood cell lines can give indirect information about the decrease of life span of erythrocytes in the peripheral blood or about the fact that they are destroyed by the spleen in a faster way. On the other hand, a decrease of the lymphoid line can give information that immunity can be weakened by a diet, especially the fatty diet. Vanadium complex with organic ligand as an addition to the tested diets intensifies the reported observation.

The observed changes of percentages of both erythroid and lymphoid lines can be either related or/and independent. In the first case, an increase of red blood cell line production independent for erythropoietin is an adaptive organism reaction to the shorting life span of erythrocytes. This stimulates red blood cell production and does not change the lymphocyte count. The second option is that both erythrocytes and lymphocytes simultaneously change: the decrease for lymphocytes and the increase for red blood cells. Another option is an influence of the tested diet and/or vanadium on renal or liver production of erythropoietin which changes the percentage of marrow red cells. An answer to these three possibilities can be given by the investigation of whole blood, bone marrow and erythropoietin together. The possibility of the iron level influence on the picture of erythroid precursors in the bone marrow as a result of the tested diets has not been excluded. Diets contained the same quantity of this element in the vitamin and mineral mix. In the group of animals with fatty diet, consumption of nutrition was smallest because calorific value in this case was biggest. This resulted in the smallest intake of iron by these animals. However, in this group of animals, percentage of erythroid precursors was the highest. The addition of vanadium complex showed an increase of food consumption and indirectly iron intake. This can probably increase erythroid precursors in all vanadium treated animals in comparison to groups not treated with vanadium. An investigation of the life span of erythrocytes and count of lymphocytes with diagnosis of total organism immunity is interesting as well. Potential shortening of the life span of erythrocytes can require an intensified organism effort for blood cell production. This also requires correct nutrition, rich in all essential substances indispensable for creation of cells in the bone marrow. Their deficiency can weaken defensive mechanisms of the organism and obstruct the pace of health recovery. Similarly, a potential reduction in oxygen transport throughout the organism increases malfunction of the body. This process must be explained in other investigations, including bone marrow cells and also peripheral blood observation. Heavy metals, some medicines, ionic radiation are very well-known factors having influence on cells in the bone marrow. However, in the case of other factors, such as diet components, knowledge is incomplete, and these types of investigation are necessary.

\section{Conclusion}

Erythroid and lymphoid lines are the most sensitive marrow cells when considering the influence of the tested diet components: fructose or fat. Their reactions are inversely proportional. The increase of the erythroid line under the influence of the test agent is parallel to the decrease of the lymphoid line. The addition of vanadium can enhance the interaction.

Acknowledgments This work was supported by grant no. K/ZBW/ 000497 of the Medical College of Jagiellonian University. We would also want to give special thanks to technicians Ewelina Gajdzik, Barbara Tatar and Iwona Zagrodnik for their help during project realization.

Open Access This article is distributed under the terms of the Creative Commons Attribution License which permits any use, distribution, and reproduction in any medium, provided the original author(s) and the source are credited.

\section{References}

1. Saad A, Palm M, Widell S, Reiland S (2000) Differential analysis of rat bone marrow by flow cytometry. Comp Haemat Int 10:97-101

2. Criswell KA, Bleavins MR, Zielinski D, Zandee JC (1998) Comparison of flow cytometric and manual bone marrow differentials in Wistar rats. Cytometry 32:9-17

3. Ulrich TR, del Castillo J (1991) The hematopoietic and mature blood cells of the rat: their morphology and the kinetics of circulating leukocytes in control rats. Exp Hematol 19:639-648

4. Reagan WJ, Irizarry-Rovira A, Poitout-Belissent F, Bolliger AP, Ramaiah SK, Travlos G, Walker D, Bounous D, Walter G, Bone Marrow Working Group of ASVCP/STP (2011) Best practices for evaluation of bone marrow in nonclinical toxicity studies. Toxicol Pathol 39:435-448

5. Pyszel A, Wróbel T, Szuba A, Andrzejak R (2005) Effect of metals, benzene, pesticides and ethylene oxide on the haematopoietic system. Med Pr 56:249-255

6. Institóris L, Siroki O, Undeger U, Basaran N, Banerjee BD, Dési I (2001) Detection of the effects of repeated dose combined propoxur and heavy metal exposure by measurement of certain toxicological, haematological and immune function parameters in rats. Toxicology 163:185-193 
7. Woo S, Krzyzanski W, Jusko WJ (2008) Pharmacodynamic model for chemotherapy-induced anemia in rats. Cancer Chemother Pharmacol 62:123-133

8. Turton JA, Andrews CM, Havard AC, Robinson S, York M, Williams TC, Gibson FM (2002) Haemotoxicity of thiamphenicol in the BALB/c mouse and Wistar Hanover rat. Food Chem Toxicol 40: 1849-1861

9. Borelli P, Barros FE, Nakajima K, Blatt SL, Beutler B, Pereira J, Tsujita M, Favero GM, Fock RA (2009) Protein-energy malnutrition halts hemopoietic progenitor cells in the G0/G1 cell cycle stage, thereby altering cell production rates. Braz J Med Biol Res 42:523530

10. Zisser H, Gong P, Kelley CM, Seidman JS, Riddell MC (2011) Exercise and diabetes. Int J Clin Pract Suppl 170:71-75

11. Uusitupa MI (1994) Fructose in the diabetic diet. Am J Clin Nutr 59:753S-757S

12. Malerbi DA, Paiva ES, Duarte AL, Wajchenberg BL (1996) Metabolic effects of dietary sucrose and fructose in type II diabetic subjects. Diabetes Care 19:1249-1256

13. Feinman RD (2011) Fad diets in the treatment of diabetes. Curr Diab Rep 11:128-135

14. Hu R, He C, Liu J, Wu Y, Li J, Feng Z, Huang J, Xi XG, Wu Z (2010) Effects of insulin-mimetic vanadyl-poly(gamma-glutamic acid) complex on diabetic rat model. J Pharm Sci 99:3041-3047

15. Li M, Ding W, Smee JJ, Baruah B, Willsky GR, Crans DC (2009) Anti-diabetic effects of vanadium(III, IV, V)-chlorodipicolinate complexes in streptozotocin-induced diabetic rats. Biometals 22: 895-905
16. Zorzano A, Palacín M, Marti L, García-Vicente S (2009) Arylalkylamine vanadium salts as new anti-diabetic compounds. J Inorg Biochem 103:559-566

17. Thompson KH, Lichter J, LeBel C, Scaife MC, McNeill JH, Orvig C (2009) Vanadium treatment of type 2 diabetes: a view to the future. J Inorg Biochem 103:554-558

18. Sartorelli DS, Franco LJ, Gimeno SGA, Ferreira SR, Cardoso MA, Japanese-Brazilian Diabetes Study Group (2009) Dietary fructose, fruits, fruit juices and glucose tolerance status in Japanese-Brazilians. Nutr Metab Cardiovasc Dis 19:77-83

19. Tappy L (2010) Fructose and metabolic diseases: new findings, new questions. Nutrition 26:1044-1049

20. Vaismana N, Niva E, Izkhakov Y (2006) Catalytic amounts of fructose may improve glucose tolerance in subjects with uncontrolled non-insulin-dependent diabetes. Clin Nutr 25:617-621

21. MacGregor JT, Tucker JD, Ziderman II, Wehr CM, Wilson RE, Friedman M (1989) Non-clastogenicity in mouse bone marrow of fructose/lysine and other sugar/amino acid browning products with in vitro genotoxicity. Food Chem Toxicol 27:715-721

22. Thompson $\mathrm{KH}$, Orvig C (2006) Vanadium in diabetes: 100 years from phase 0 to phase I. J Inorg Biochem 100:1925-1935

23. Föller M, Sopjani M, Mahmud H, Lang F (2008) Vanadate-induced suicidal erythrocyte death. Kidney Blood Press Res 31:87-93

24. Goyer RA, Clarkson TW (2001) Toxic effects of metals. In: Klaassen CD (ed) Casarett \& Doull's toxicology: the basic science of poisons. The McGraw-Hill, New York

25. Weiss DJ (2010) Myelonecrosis and acute inflammation. In: Schalm's veterinary hematology. Blackwell Publishing Ltd. 